Paula Muniz do Amaral ${ }^{1}$

José Tavares-Neto²

\section{Exposição ocupacional a material biológico por pessoal de saúde: construção e proposição de instrumentos avaliativos*}

\author{
Healthcare personnel's occupational exposure to biological \\ material - elaboration and proposition of assessment instruments
}

${ }^{1}$ Programa de Pós-graduação em Saúde, Ambiente e Trabalho (PPgSAT) da Faculdade de Medicina da Bahia (FMB) da Universidade Federal da Bahia (UFBA) - Salvador (BA), Brasil.

2 Professor Livre-Docente da Faculdade de Medicina da Bahia (FMB) da Universidade Federal da Bahia (UFBA) - Salvador (BA), Brasil.

*Artigo baseado na dissertação de Mestrado de Paula Muniz do Amaral intitulada Exposição ocupacional a material biológico: proposição de instrumento à avaliação formativa do pessoal de saúde, apresentada em 2009 ao Programa de Pós-graduação em Saúde, Ambiente e Trabalho da Faculdade de Medicina da Universidade Federal da Bahia.

Contato:

Paula Muniz do Amaral

Faculdade de Medicina da Bahia (FMB) / UFBA.

Largo do Terreiro de Jesus, Centro Histórico

CEP: 40.025-010 - Salvador, BA, Brasil.

E-mail:

aluapmuniz@hotmail.com

Apoio: Fundação de Amparo à Pesquisa do Estado da Bahia (FAPESB) - Termo de Outorga no BOL 1029/2007 - Bolsa - Mestrado FCE
Recebido: 25/05/2009

Revisado: 20/12/2009

Aprovado: 22/12/2009

\section{Resumo}

No Brasil, os indicadores de exposição aos agentes biológicos apresentam lacunas acerca dos conhecimentos, das atitudes e dos comportamentos do pessoal de saúde e não há instrumento validado para avaliação desses aspectos. Neste trabalho, o objetivo foi elaborar questionários para a avaliação institucional e do pessoal de saúde sobre a exposição ocupacional a material biológico utilizando a literatura como fonte. Foram utilizadas as bases Medline, Lilacs e Scopus a partir de palavras-chave, termos análogos e descritores associados ao tema. Dos 557 artigos pré-selecionados, 91 (16,3\%) foram efetivamente incluídos no estudo. Para obtenção, análise e interpretação dos dados, foram utilizadas técnicas de análise de conteúdo e de análise de dados secundários. Com base nesse estudo, foram definidas categorias e subcategorias temáticas que orientaram a construção de dois questionários: um para avaliação institucional e outro dirigido ao pessoal de saúde. A validade aparente dos instrumentos foi realizada por sete avaliadores ad hoc e independentes. Esses questionários, após estudo de validação em campo, poderão ser aplicados na investigação científica e na avaliação de aspectos associados ao tema aqui estudado, assim como fornecer dados à elaboração, à implantação e ao monitoramento de práticas profissionais e de gestão.

Palavras-chave: avaliação de programas e instrumentos de pesquisa; exposição ocupacional; líquidos corporais; pessoal de saúde; conhecimentos, atitudes e prática em saúde.

\section{Abstract}

In Brazil, biologic agents exposure lack information about healthcare workers' knowledge, attitudes and behavior, and there is no valid instrument to assess these issues. The purpose of the present work was to develop questionnaires to assess institutions and health care workers about their occupational exposure to biological material, using literature as a data source. Medline, Scopus and Lilacs databases were searched by key words, analogous expressions, and descriptors related to the subject. From the 557 preselected articles, 91 (16.3\%) were effectively included in the study. To obtain, analyze, and interpret data, contend and secondary data analysis techniques were selected. Thematic categories and sub-categories were defined based on this study, and they guided the construction of two questionnaires - one for institutional assessment and the other to assess healthcare workers. Seven independent ad hoc reviewers evaluated the apparent validity of the instruments. After the validation of these questionnaires in the field, they can be used for scientific research and for assessment of the aspects associated to the issues studied in this paper, as well as provide data for elaboration, implementation, and monitoring of professional practices and management.

Keywords: evaluation of research programs and tools; occupational exposure; body fluids; healthcare personnel; health knowledge, attitudes and practice. 


\section{Introdução}

Apesar dos avanços nos marcos legais ou normativos, a real situação brasileira sobre os indicadores de exposição dos profissionais de saúde aos agentes biológicos apresenta inúmeras lacunas, visto que são crescentes os riscos de acidentes desta natureza e estão presentes nas atividades dos profissionais de saúde em decorrência das precárias condições de trabalho em muitas instituições de saúde, como também pelo aumento da prevalência de portadores dos vírus da imunodeficiência humana (VIH) e das hepatites B (VHB) e C (VHC). Não obstante, no Brasil não há dados sistematizados, dos vários níveis de atenção à saúde, sobre a ocorrência dos acidentes com material perfurocortante e que permitam conhecer a real magnitude do problema.

Dessa forma, a vulnerabilidade do pessoal de saúde está ligada às atividades, aos comportamentos e às vivências relativas à organização e ao processo de trabalho, como também às condições sociais mais amplas, ao acesso aos serviços e à existência de políticas públicas de biossegurança. Por sua vez, na atualidade, a diversidade dos campos de atuação dos profissionais de saúde exige delineamentos específicos a cada profissão ou atividade da área da saúde. Nesse contexto, os profissionais de saúde devem estar dotados de competências (conhecimentos, habilidades e atitudes) que possibilitem a sua interação e atuação multiprofissional, promovendo e executando ações integrais de saúde que beneficiem indivíduos e comunidades (ALMEIDA, 1999).

Portanto, conhecer o perfil do pessoal de saúde, das exposições a material biológico e as condutas adotadas ao planejamento e à avaliação das medidas de prevenção têm estreita vinculação com a disponibilidade de dados e a qualidade da informação, esta dependente, sobretudo, da adequada coleta de dados gerados no local onde ocorre o acidente. É também na unidade de saúde, de qualquer nível ou grau de complexidade, que os dados devem primariamente ser sistematizados para se constituírem em adequado instrumento de informação, capaz de subsidiar todo o processo de planejamento, avaliação, manutenção e aprimoramento das ações (BRASIL, 2005).

Não obstante, ainda não há disponível instrumento de avaliação ou de coleta de dados, aplicável ao pessoal de saúde ou às unidades de saúde com diversos níveis de complexidade. Em vista disso, é ainda muito limitada a capacidade de avaliar os conhecimentos, as atitudes e as práticas dos profissionais de saúde sobre exposição ocupacional a material biológico em serviços de saúde ou as características institucionais envolvidas nesse processo. No entanto, nas avaliações dessa natureza, o mais usual é a aplicação de questionários (elaborados sem procedimentos técnicos e não validados) em estudos transversais ou epidemiológicos, os quais permitem a obtenção de informações, de modo mais ágil e com menor custo (BOYNTON; GREENHALGH, 2004). Por isso, o objetivo deste trabalho foi elaborar questionários, a serem posteriormente validados, para a avaliação institucional e do pessoal de saúde sobre a exposição ocupacional a material biológico.

\section{Metodologia}

Para elaboração dos questionários foram utilizados artigos selecionados da literatura especializada e, para obtenção, análise e interpretação dos dados, foi utilizada a análise de dados secundários (FIGUEIREDO; TAVARES-NETO, 2001; HEARST et al., 2003) e as técnicas da análise de conteúdo (BARDIN, 2008) destes mesmos artigos. Na etapa final, e após sistemática revisão pelos autores, aos dois questionários propostos, foi aplicada a análise teórica dos itens, conforme sugere Pasquali (1998), com o propósito de ampliar a validade interna dos instrumentos.

\section{Análise secundária de dados}

Nesta primeira fase do estudo, foram utilizadas as bases de dados de periódicos científicos Medline ${ }^{\circledR}$, Lilacs e Scopus ${ }^{\circledR}$ para a busca de artigos ou outras publicações, desde o ano inicial da base de dados até 4 de Março de 2008, a partir de palavras-chave, termos análogos e descritores associados ao problema desta pesquisa: como são avaliados os conhecimentos, as atitudes e as práticas do pessoal de saúde sobre exposição ocupacional a material biológico em serviços de saúde?

Após a busca dos artigos, a fase de pré-seleção foi fundamentada na leitura e na análise do título dos mesmos e do resumo de cada publicação (quando disponível), além da verificação dos dados da ficha bibliográfica da publicação (e.g., idioma). Nesta fase, quando as informações disponíveis permitiam, a publicação foi pré-selecionada com base nos critérios: de inclusão, (1) estudos sobre exposição ocupacional a material biológico em pessoal de saúde, descrito nos idiomas português, espanhol ou inglês; (2) estudos sobre exposições ocupacionais (percutâneos, mucocutâneos, cutâneos e mordeduras humanas) com líquidos corporais que podem trazer riscos de transmissão de agentes etiopatogênicos; (3) publicações em revistas nacionais ou estrangeiras, disponíveis em bibliotecas de Salvador (Bahia), por meio eletrônico, pela Bireme ou pelo sistema Comut; e (4) nos estudos incluídos, foi considerado todo o pessoal de saúde - definido como o conjunto de trabalhadores que, tendo formação ou capacitação específica, prática ou acadêmica, trabalha exclusivamente nos serviços ou atividades de saúde; de exclusão, (1) entre os resumos selecionados, foram excluídos os artigos não escritos nas línguas portuguesa, espanhola ou inglesa; (2) excluídos artigos que apresentavam pessoal de saúde sem envolvimento com materiais biológicos; (3) publicações não recuperadas nas bibliotecas de Salvador, por meio eletrônico, pela Bireme ou pelo 
sistema Comut; e (4) excluídos artigos sobre doenças e agravos não relacionados com a exposição ocupacional a material biológico.

A fase de seleção da publicação foi realizada após a recuperação da versão completa do texto pré-selecionado, por meio da leitura da mesma e observando os critérios supracitados de seleção.

\section{Análise de conteúdo}

Nesta análise, foram utilizadas como referencial as recomendações de Bardin (2008) e adotada a análise por categorias que funciona por operações de desmembramento do texto em unidades, em categorias, sendo ordenada segundo o reagrupamento analógico. Entre as diferentes possibilidades de categorização, foi selecionada a investigação por temas, ou a análise temática, que tem as vantagens de ser rápida e eficaz (BARDIN, 2008).

Dentre os procedimentos metodológicos da análise de conteúdo, este método pode ser dividido em três fases: pré-análise, exploração dos artigos e tratamento dos resultados e interpretação.

Na pré-análise, fase de organização e das primeiras análises dos artigos selecionados, há três momentos: a escolha dos documentos através dos títulos e resumos; a referência aos índices (palavras repetidas); e a elaboração de indicadores (são os índices associados as suas respectivas frequências, que se transformam em indicadores) que fundamentam a interpretação final. Nessa etapa, foi realizada a leitura de todos os títulos e resumos dos artigos selecionados e aplicados os critérios de inclusão e exclusão pré-estabelecidos.

Na fase de exploração dos artigos, foram analisados os artigos para detectar as semelhanças e as diferenças entre os mesmos, com a codificação e o recorte dos aspectos convergentes. O processo de categorização foi o passo seguinte. Durante o processo de leitura completa dos artigos, foram registradas as categorias e as subcategorias temáticas e estas, classificadas por semelhanças, na medida em que foram encontradas no texto. A codificação corresponde à transformação dos dados brutos do texto, à transformação por recorte (escolha das unidades), à classificação e à agregação (escolha das categorias) e à enumeração (escolha das regras de contagem), que permitem atingir a representação do conteúdo (BARDIN, 2008). A categorização é a operação de classificação de elementos constitutivos do conjunto por diferenciação e, seguidamente, por reagrupamento segundo gênero (analogia), com os critérios previamente definidos (BARDIN, 2008). O critério de categorização, definido para esta análise de conteúdo, foi o léxico: classificação das palavras segundo o seu sentido, com emparelhamento dos sinônimos e dos sentidos próximos (BARDIN, 2008).

$\mathrm{Na}$ fase de tratamento dos resultados e interpretação, optou-se pela análise quantitativa, em que os resultados brutos são tratados de maneira a serem expressivos e válidos. Operações estatísticas simples (frequência relativa e absoluta) permitem estabelecer quadros de resultados, gráficos, fluxogramas, os quais consolidam e põem em destaque as informações fornecidas pela análise.

\section{Elaboração dos itens do questionário}

Para elaborar os itens do questionário, foram utilizados os critérios pressupostos por Pasquali (1998): critério comportamental; de objetividade ou de desejabilidade; de simplicidade; de clareza; da relevância; de precisão; da variedade; da modalidade; de tipicidade; e de credibilidade.

Para maximizar a validade do conteúdo, o questionário foi construído em torno das categorias e subcategorias temáticas e das principais questões levantadas nos artigos selecionados pela análise do conteúdo.

Após a elaboração e a revisão pelos autores e, posteriormente, pelos pós-graduandos do curso de Mestrado (AMARAL, 2009), de diferentes áreas da saúde ou de áreas afins (gestão pública e segurança do trabalho), um dos pressupostos foi de que os questionários pudessem ser aplicados em instituições públicas, privadas ou filantrópicas e ao pessoal de saúde de todos os níveis de escolaridade, técnico e/ou hierárquico da unidade de saúde.

$\mathrm{Na}$ etapa final, foi realizada a análise teórica dos itens. Esta análise tem como fundamento as recomendações de Pasquali (1998), é realizada por avaliadores ou juízes (referees) e pode ser de dois tipos: análise semântica (compreensão dos itens) e análise sobre a pertinência dos itens. A análise teórica dos itens dos questionários foi realizada por sete (7) avaliadoras ad hoc de sete instituições do Brasil, localizadas em Florianópolis (SC), Maceió (AL), Porto Velho (RO), Recife (PE), Salvador (BA), São João Batista (SC) e São Paulo (SP), com diferentes formações acadêmicas ( 3 médicas, 3 enfermeiras e 1 bióloga) e com atuação em setores de serviços de saúde vinculados à proteção do profissional de saúde, ao controle de infecção hospitalar, à pesquisa ou à área administrativa afim destes serviços (AMARAL, 2009). Para isso, após prévio contato telefônico, as avaliadoras receberam carta e mensagem eletrônica, ambas com os questionários propostos anexos e com instruções sobre o roteiro de avaliação para cada uma das perguntas ou partes do questionário (institucional e pessoal de saúde), além da solicitação de que correções, sugestões ou propostas de adendos fossem descritas no próprio questionário, com fonte de cor vermelha, e este devolvido como anexo de mensagem eletrônica (AMARAL, 2009).

Este estudo, como também o Termo de Consentimento Livre e Esclarecido, foi aprovado através do Parecer/ Resolução Aditiva no 159/2007, pelo Comitê de Ética em Pesquisa da Maternidade Climério de Oliveira (Salvador, BA), da Universidade Federal da Bahia, credenciado pela Comissão Nacional de Ética em Pesquisa (CONEP).

A análise dos resultados foi descritiva, pela apresentação das frequências absoluta e relativa dos resultados quantitativos. 


\section{Resultados}

Na pesquisa sistemática da literatura, após aplicar as estratégias de busca dos artigos nos bancos de dados Medline (de 1966 a 4/3/2008), Scopus (de 2004 a 4/3/2008) e Lilacs (de 1982 a 4/3/2008), foram encontrados 557 artigos em periódicos nacionais e internacionais, mas todos estes foram publicados a partir do ano de 1986.

Nos 557 artigos pré-selecionados, após aplicar os critérios de inclusão e exclusão, foram selecionados 119 $(21,3 \%)$ e destes foram localizados 111 (19,9\%). Porém, após impressão e leitura, ainda foram excluídos 20 artigos (duplicatas, editoriais ou recomendações genéricas de serviço), restando $91(16,3 \%)$ artigos como amostra final. Portanto, foram excluídos 82,8\% (461/557) dos artigos pré-selecionados. Entre os 91 artigos selecio- nados, só seis $(6,6 \%)$ eram nacionais e publicados em periódicos brasileiros.

Pela análise de conteúdo, dos 91 títulos dos artigos selecionados, foram obtidos 24 índices. A Tabela 1 apresenta os índices selecionados e a proporcionalidade em relação aos títulos dos artigos após a etapa de codificação. Entre as palavras repetidas, exposição e sangue foram as mais frequentes, respectivamente, em $42,8 \% \mathrm{e}$ 29,7\% das publicações selecionadas (Tabela 1).

A partir da repetição de frequências dos índices (Tabela 1), foram definidas 7 categorias e 21 subcategorias, apresentadas no Quadro 1. Concluídas estas fases preliminares, foram elaborados dois questionários, institucional e aquele a ser aplicado ao pessoal de saúde da instituição, ambos com o total de 117 questões. Isto após a análise e discussão de cada sugestão recebida das sete avaliadoras.

Tabela 1 Frequência de ocorrência das palavras nos 91 títulos dos artigos localizados

\begin{tabular}{|c|c|c|}
\hline $\begin{array}{c}\text { Índices } \\
\text { (ocorrência das palavras) }\end{array}$ & $\begin{array}{l}\text { Frequência } \\
\text { absoluta }\end{array}$ & $(\%)$ \\
\hline Acidente & 9 & 9,9 \\
\hline Conhecimentos, atitudes e prática & 9 & 9,9 \\
\hline Dispositivos & 1 & 1,1 \\
\hline Diretrizes & 2 & 2,2 \\
\hline Exposição & 39 & 42,8 \\
\hline $\mathrm{EPI}$ & 1 & 1,1 \\
\hline Fluidos; líquidos corporais; material biológico & 14 & 15,4 \\
\hline Gestão & 8 & 8,8 \\
\hline Infecção de origem sanguínea & 12 & 13,2 \\
\hline Imunização & 2 & 2,2 \\
\hline Lesão/ferimento & 25 & 27,5 \\
\hline Mucocutânea & 1 & 1,1 \\
\hline Orientações & 1 & 1,1 \\
\hline Percutânea & 11 & 12,1 \\
\hline Pós-exposição & 1 & 1,1 \\
\hline Prevenção & 4 & 4,4 \\
\hline Precaução & 2 & 2,2 \\
\hline Precaução universal & 4 & 4,4 \\
\hline Proteção & 1 & 1,1 \\
\hline Riscos & 13 & 14,3 \\
\hline Sangue & 27 & 29,7 \\
\hline Subnotificação & 3 & 3,3 \\
\hline Vigilância & 3 & 3,3 \\
\hline
\end{tabular}


Quadro 1 Categorias e subcategorias temáticas

\begin{tabular}{|l|l|}
\hline \multicolumn{1}{|c|}{ Categorias } & \multicolumn{1}{|c|}{ Subcategorias } \\
\hline \multirow{3}{*}{ 1. Saúde do trabalhador } & 1.1 Riscos \\
& 1.2 Exposição \\
& 1.3 Experiência Profissional \\
\hline 2. Infecções transmitidas pelo sangue, e fluidos & 2.1 Conhecimentos sobre o HIV e os vírus das hepatites B e C. \\
corporais & 2.2 Outros \\
\hline \multirow{3}{*}{ 3. Precauções padrão } & 3.1 Conhecimentos, atitudes e prática \\
& 3.2 Práticas de manipulação \\
& 3.3 Recomendações específicas \\
\hline \multirow{3}{*}{ 4. Exposição ocupacional } & 4.1 História de exposição mucocutânea e lesão percutânea. \\
& 4.2 Circunstância envolvendo a exposição \\
& 4.3 Equipamentos de Proteção Individual (EPI) \\
\hline \multirow{2}{*}{ 5. Profilaxia pós-exposição } & 4.4 Objetos perfurocortantes \\
\hline \multirow{2}{*}{ 6. Notificação } & 4.5 Variedades de dispositivos \\
& 4.6 Número de horas trabalhadas \\
\hline \multirow{2}{*}{ 7. Políticas de prevenção } & 5.1 Procedimentos recomendados \\
\hline
\end{tabular}

O questionário institucional (Apêndice 1), a ser respondido pelo gestor principal, tem 35 questões, enquanto o destinado ao pessoal de saúde (Apêndice 2) tem 82 questões. Ambos os questionários foram dispostos por blocos em torno das categorias e das subcategorias temáticas investigadas. A maioria das perguntas, em ambos os questionários, foi elaborada com o formato fechado, com várias respostas ou alternativas possíveis, e o conteúdo destas perguntas abordava aspectos sobre: padrões de ação, procedimentos ou condutas; comportamentos, presentes ou passados, relacionados às práticas técnicas, crenças, sentimentos ou orientações; e razões conscientes concernentes a crenças, sentimentos, orientações ou comportamentos.

Nos 91 artigos, o questionário foi o instrumento utilizado para coleta de dados junto ao pessoal de saúde em 58 (63,7\%) publicações selecionadas, mas em apenas $1(1,7 \%)$ delas houve a prévia validação do instrumento. Nos seis artigos nacionais, 2 (33,3\%) utilizaram questionário, igualmente não validados.

No total dos artigos, só 12 (13,2\%) descreveram os critérios utilizados para elaboração do questionário utilizado na investigação; e $4(4,4 \%)$ das publicações selecionadas referiram a revisão de literatura como fonte para elaboração do questionário aplicado à coleta dos dados. O uso combinado das duas metodologias (quantitativa e qualitativa) foi utilizado por $1(1,1 \%)$ artigo dos trabalhos selecionados.

\section{Discussão}

As três bases de dados pesquisadas (Medline, Scopus e Lilacs) compreendem a literatura científica e técnica relativa às ciências da saúde em geral e cobrem a quase totalidade das revistas indexadas em todo o mundo ${ }^{3}$. Por conta da ampla heterogeneidade dos periódicos, é essencial a pesquisa bibliográfica de modo sistemático e a observação dos critérios de inclusão e de exclusão pré-estabelecidos. Dessa forma, há maior possibilidade da exclusão dos artigos, na fase de pré-seleção, de muitos trabalhos sem nexo direto com o objetivo do estudo proposto, como também aqueles escritos em línguas de mais difícil acesso aos autores (e.g., mandarim, polonesa, dinamarquesa, entre outras).

Mesmo assim, chama à atenção a exclusão de 82,8\% dos artigos pré-selecionados. No entanto, taxas semelhantes foram assinaladas em outros estudos de análise secundária de dados da literatura revistos por Amaral (2009), e isto reforça a necessidade da busca bibliográfica sistemática, do contrário, torna a pesquisa inexequível por conta do grande número de publicações sobre assuntos afins ou conteúdos que não contemplam o objetivo do estudo em desenvolvimento.

Não obstante, a limitação de acesso às publicações escritas em línguas não incluídas introduz o viés de seleção e isso pode ser a causa de falsas inferências ou interpretações. Contudo, neste trabalho, os 91 artigos incluídos (AMARAL, 2009), tanto os nacionais, como os internacionais, foram publicados nos periódicos de maior impacto na área estudada. Portanto, é suposto

${ }^{3}$ BVS. Biblioteca Virtual em Saúde. Literatura Científica e Técnica. Ciências da Saúde em Geral. Disponível em: < http://www.bireme.br/php/level.php?lang $=$ pt\&component $=107 \&$ item $=107>$. Acesso em: 15 jan. 2009. 
que os 91 artigos sejam representativos sobre o conhecimento estudado neste trabalho e expressem o estado da arte no hemisfério ocidental.

Na análise de conteúdo dos 91 artigos selecionados, foram feitas inferências e realizadas interpretações para elaboração dos itens do questionário com base nos resultados alcançados no estudo e na fundamentação teórica (AMARAL, 2009). Nesta análise, foram seguidas orientações de Pasquali (1998), Minayo (2007) e Bardin (2008).

É importante notar que no processo de elaboração desses tipos de instrumentos, anexos deste trabalho, os itens não são inseridos de modo aleatório, mas em acordo com as definições operacionais do construto, após exaustiva análise dos fundamentos teóricos, e com as evidências (dados) empíricas disponíveis na literatura, conforme as recomendações de Pasquali (1998).

Sendo assim, com o desmembramento dos títulos dos artigos em unidades e após a realização da análise quantitativa sistemática para identificar a frequência relativa e absoluta do tema escolhido, a proporcionalidade e as frequências dos índices, foram definidas as 7 categorias e as 21 subcategorias temáticas, fonte principal para a elaboração dos itens dos 2 questionários propostos (AMARAL, 2009).

O questionário de avaliação institucional destinado ao gestor tem como propósito conhecer os protocolos de prevenção da instituição à exposição a material biológico em relação a: medidas de prevenção e gerenciais; treinamento e educação; controle médico e registro; e vigilância. Concomitantemente, o questionário destinado ao pessoal de saúde possibilita a análise de características pessoais, aptidões, potencialidades e talentos, tendo sido as questões reunidas por grupos temáticos seguindo as categorias selecionadas para melhor fluxo no preenchimento do instrumento. Todavia, para o pessoal de saúde com formação elementar, há necessidade de que o instrumento seja preenchido sob supervisão e, para isso, foi proposto que no estudo-piloto os procedimentos operacionais necessários sejam adequadamente avaliados com vistas à redução do viés de observação (AMARAL, 2009).

A avaliação da validade interna, realizada pelas avaliadoras ad hoc, através da análise teórica dos itens, é considerada por Pasquali (1998) como etapa anterior dos estudos piloto e de validação, visto que as avaliadoras fazem parte da população-alvo com maior habilidade e treinamento; e, desta forma, há maiores garantias de alcançar a validade aparente do instrumento. No entanto, esta análise trata-se de uma avaliação superficial e não deve ser usada como critério isolado ou como substituto dos estudos-piloto e de validação, inclusive porque este tipo de validação interna não confere propriedades de medida (PASQUALI, 1998).

Por isso, no estudo-piloto proposto, já aprovado pelo Comitê de Ética em Pesquisa da Maternidade Climério de Oliveira, estes instrumentos deverão ser preliminarmente reavaliados, com a inclusão na amostra, a ser pesquisada, de instituições e de pessoas procedentes de mais ampla área territorial do Brasil.
A relevância de estudos desta natureza é porque no Brasil não há instrumentos validados com o propósito de avaliar os riscos de exposição a material biológico ou os impactos das medidas de prevenção e de controle. Sem a adequada coleta de dados, não há informação para planejamento, avaliação, manutenção e aprimoramento das ações por parte dos gestores de unidades de saúde e das entidades que resguardam os direitos dos trabalhadores (AMARAL, 2009). Contudo, paradoxalmente, há excesso de normas ou legislações especificas, como apresentado na publicação do Ministério da Saúde/Organização Pan-Americana da Saúde em Doenças Relacionadas ao Trabalho: manual de procedimentos para os serviços de saúde, em que estão as bases legais para as ações de saúde do trabalhador no sentido de cumprir a determinação constitucional de dar atenção à saúde do trabalhador, ao atendimento dos princípios de universalidade, à equidade, à integralidade e ao controle social que regem o Sistema Único de Saúde (BRASIL, 2001). Aliado a este quadro, as instituições formadoras ainda têm conteúdos curriculares, teóricos ou práticos sem a devida valorização dos métodos e meios voltados à biossegurança de alunos, docentes, profissionais de saúde, pacientes, entre outros. A biossegurança não se resume somente a normas de prevenção e controle; a sua dimensão científica requer das pessoas uma formação educacional adequada à compreensão e à execução desses objetivos (DE BONIS; COSTA, 2008). Por sua vez, dos 85 artigos selecionados, publicados em periódicos internacionais, bem como dos seis artigos nacionais, apenas um artigo utilizou instrumento validado. Portanto, neste contexto, há muitas perspectivas de estudos que visem estabelecer indicadores e instrumentos de avaliação sobre a qualidade das medidas de controle e de prevenção, até porque, como agravante dessa situação, especialmente no Brasil, há um aparente descompasso entre a qualidade e a quantidade dos dados disponíveis, e das medidas de avaliação sobre a exposição ocupacional a material biológico.

\section{Conclusão}

A avaliação dos aspectos relacionados à organização do trabalho e suas repercussões sobre a saúde do trabalhador tem sido objeto de estudos mediante uso de formulários e questionários. O uso destes instrumentos permite a obtenção de informações acerca de conhecimentos, atitudes, crenças e comportamentos do público-alvo.

Na pesquisa sistemática da literatura, realizada neste estudo, não foi identificado instrumento validado para avaliar conhecimentos, atitudes e práticas do pessoal de saúde sobre exposição ocupacional a material biológico; portanto, acentua-se a importância no desenvolvimento deste tipo de instrumento, a ser aplicado tanto na investigação científica, como nas unidades de saúde, como uma ferramenta de gestão. Os dois questionários que foram desenvolvidos e estão sendo propostos, quando validados, permitirão avaliar os aspectos associados ao tema desta investigação, bem como fornecer dados à elaboração, à implantação e ao monitoramento de práticas profissionais e de gestão. 


\section{Referências}

ALMEIDA, M. J. Ensino médico e o perfil do profissional de saúde para o século XXI. Interface - Comunicação, Saúde, Educação. v. 3, n. 4, 1999. Disponível em: < http://www.interface.org.br/revista4/ debates1.pdf > . Acesso em: 23 jan. 2009.

AMARAL, P. M. Exposição ocupacional a material biológico: proposição de instrumento à avaliação formativa do pessoal de saúde. 2009. 182 f. Dissertação (Mestrado em Saúde, Ambiente e Trabalho)-Faculdade de Medicina da Bahia, Universidade Federal da Bahia, Salvador, 2009.

BARDIN, L. Análise de conteúdo. Lisboa: Edições 70, 2008.

BOYNTON, P. M.; GREENNHALGH, T. Hands-on guide to questionnaire research. Selecting, designing, and developing your questionnaire. British Medical Journal, v. 328, p. 1312-1315, 2004.

BRASIL. Ministério da Saúde. Organização Pan-Americana da Saúde no Brasil. Doenças relacionadas ao trabalho: manual de procedimentos para os serviços de saúde. Brasília, 2001. (Série A. Normas e Manuais Técnicos; n.114).

. Ministério da Saúde. Secretaria de Vigilância em Saúde. Guia de vigilância epidemiológica. 6. ed. Brasília, 2005.
DE BONIS, M; COSTA, M. A. F. Educação em biossegurança e bioética: articulação necessária em biotecnologia. Revista Ciência \& Saúde Coletiva. Rio de Janeiro, 2008. Disponível em: <http://www.abrasco.org. br/cienciaesaudecoletiva/artigos/artigo_int.php?id_ artigo $=2796>$. Acesso em: 16 mai. 2009.

FIGUEIREDO, G. C.; TAVARES-NETO, J. Estruturação de um banco de dados para análise secundária de informações em relatos ou série de casos. Revista Brasileira de Ortopedia, São Paulo, v. 36, p. 407-411, 2001.

HEARST, N. et al. Pesquisa com dados existentes: análise de dados secundários, estudos suplementares e revisões sistemáticas. In: HULLEY, S. B. et al. Delineando a pesquisa clínica. Uma abordagem epidemiológica. 2. ed. Porto Alegre: Artmed, 2003. p. 225-244.

MINAYO, M. C. S. O desafio da pesquisa social. In: MINAYO, M. C. S.; DESLANDES, S. F.; GOMES, R. Pesquisa social: teoria, método e criatividade. 26. ed. Rio de Janeiro: Vozes, 2007. p. 9-29

PASQUALI, L. Princípios de elaboração de escalas psicológicas. Revista de Psiquiatria Clínica, São Paulo, v. 25, n. 5, p. 206-213, 1998. Edição Especial. 


\section{Apêndice 1 Questionário - Instituição}

Exposição ocupacional a material biológico: conhecimentos, atitudes e práticas do pessoal de saúde Responsável: gestor principal da instituição

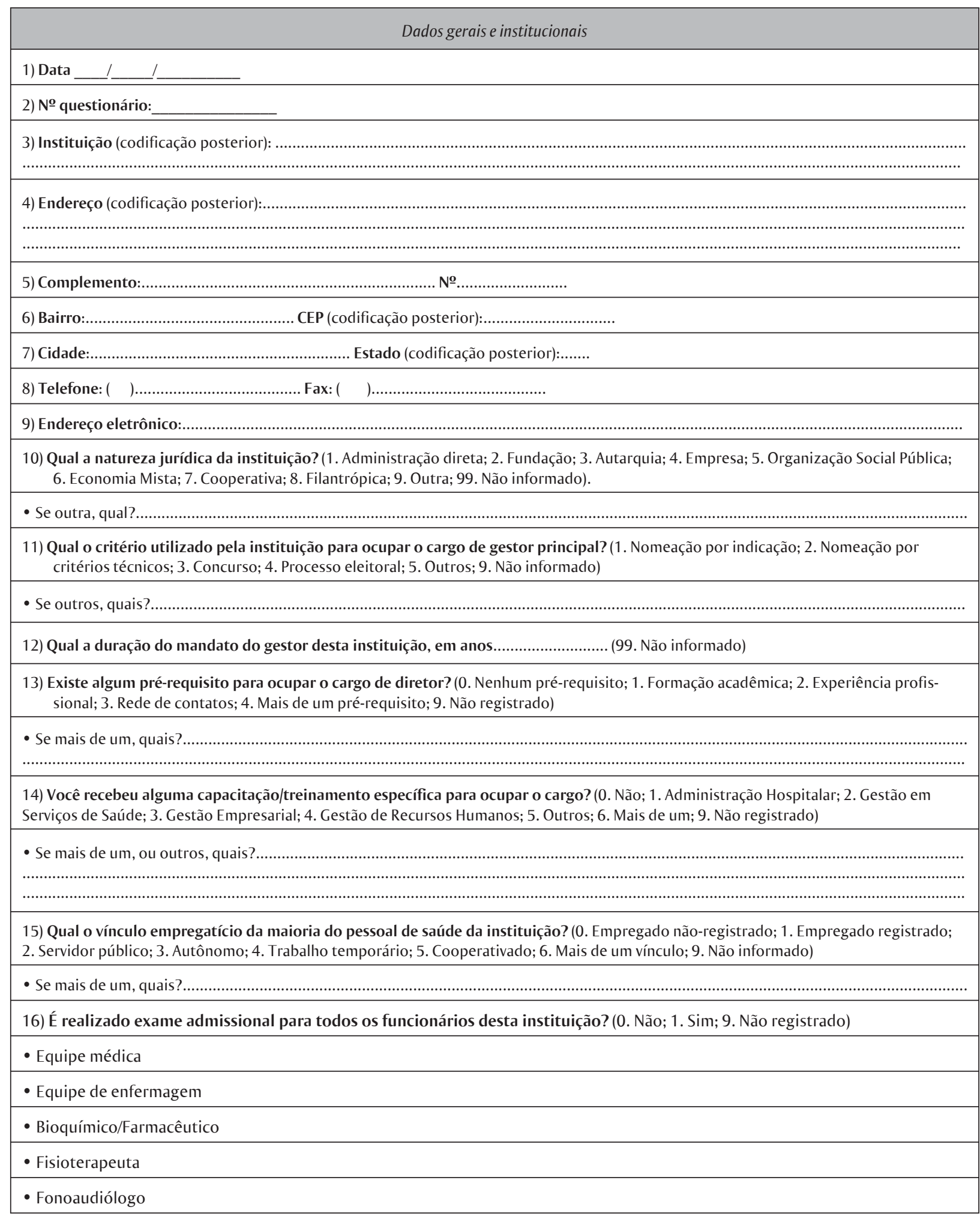


- Odontólogo

- Técnicos e auxiliares de enfermagem e laboratório;

- Serviços gerais: Limpeza, lavanderia;

- Outros, quais?

17) O programa de controle médico de saúde ocupacional (PCMSO) está implantado nesta instituição? (0. Não; 1 . Sim; 9. Não registrado)

- Através da execução e do acompanhamento dos resultados dos exames médicos obrigatórios;

- Realização de exames periódicos;

- Realização de exames de mudanças de função e retorno ao trabalho;

- Através da prevenção, rastreamento e diagnóstico precoce dos agravos à saúde relacionados ao trabalho;

- Estabelecimento equipado com material necessário à prestação de primeiros socorros;

- Outros, quais? .

18) Qual a periodicidade dos treinamentos para o pessoal de saúde desta instituição? (0. Não tem; 1. Não tem periodicidade certa; 2. Anual; 3. Semestral; 4. Trimestral; 5. Mensal; 9. Não registrado)

19) Quantos equipamentos de proteção individual (EPI) são disponibilizados para cada profissional? (0. Não disponibilizado; 1 . De acordo com a necessidade do profissional; 2. Luvas, aventais, gorros, óculos - de acordo com o risco; 3 . Luvas, aventais, gorros, óculos - em quase todos os procedimentos; 4. Luvas, aventais, gorros, óculos - em todos os procedimentos; 9. Não registrado).

20) Em caso de exposição a material biológico, quais as cinco (5) principais condutas estabelecidas por esta instituição? (00. Se não houver conduta estabelecida; 99. Não informado)

21) Em caso de exposição a material biológico, esta instituição possui profilaxia pós-exposição (PPE)? (0. Não; 1. Sim; 9. Não registrado)

- Imunização

- Aconselhamento/Teste rápido para anti-HIV;

- Medicação antirretroviral / acompanhamento;

- Encaminha para Hospital/ Centro de Referência;

22) A vigilância de acidentes com material biológico está implantada nesta instituição? (0. Não está implantada na instituição; 1. Está em fase de implantação; 2. Está implantada há menos de 12 meses; 3. Foi implantada há mais de 12 meses; 9 . Não registrado)

23) Qual o setor responsável pela notificação dos acidentes com material biológico? ( 0 . Não há setor específico; 1 . Setor de enfermagem; 2. Comissão de Controle de Infecção Hospitalar (CCIH); 3. Serviço de Controle de Infecção Hospitalar (SCIH); 4. Núcleo de Epidemiologia Hospitalar ou clínica; 9. Não registrado)

24) Qual o fluxo da informação (ficha de notificação dos acidentes com material biológico) estabelecido pela instituição? ( 0 . Não há fluxo estabelecido; 1. Setor de enfermagem; Centro Municipal de Saúde; Coord. de Programas de Epidemiologia; Secretaria Estadual; 2. CCIH ou SCIH; Centro Municipal de Saúde; Coord. de Programas de Epidemiologia; Secretaria Estadual; Ministério da Saúde; 3. Núcleo de Epidemiologia Hospitalar ou clínica; Centro Municipal de Saúde; Coord. de Programas de Epidemiologia; Secretaria Estadual; Ministério da Saúde; 9. Não registrado)

25) Qual a periodicidade dos informes e/ou boletins epidemiológicos divulgados para o pessoal de saúde? (0. Não produzimos informes, nem boletins epidemiológicos; 1. Anual; 2. Semestral; 3. Trimestral; 4. Bimensal; 5. Mensal; 6. Quinzenal; 7. Semanal; 8. Boletim diário via site da instituição ou diário por outro veículo; 9. Não informado)

26) Tem cópias desses exemplares para nos disponibilizar? (0. Não temos cópias disponíveis; 1 . Estão disponíveis em cada setor da instituição; 2. As informações estão afixadas no mural da recepção; 3. Estão disponíveis no site da instituição; 9. Não informado) 


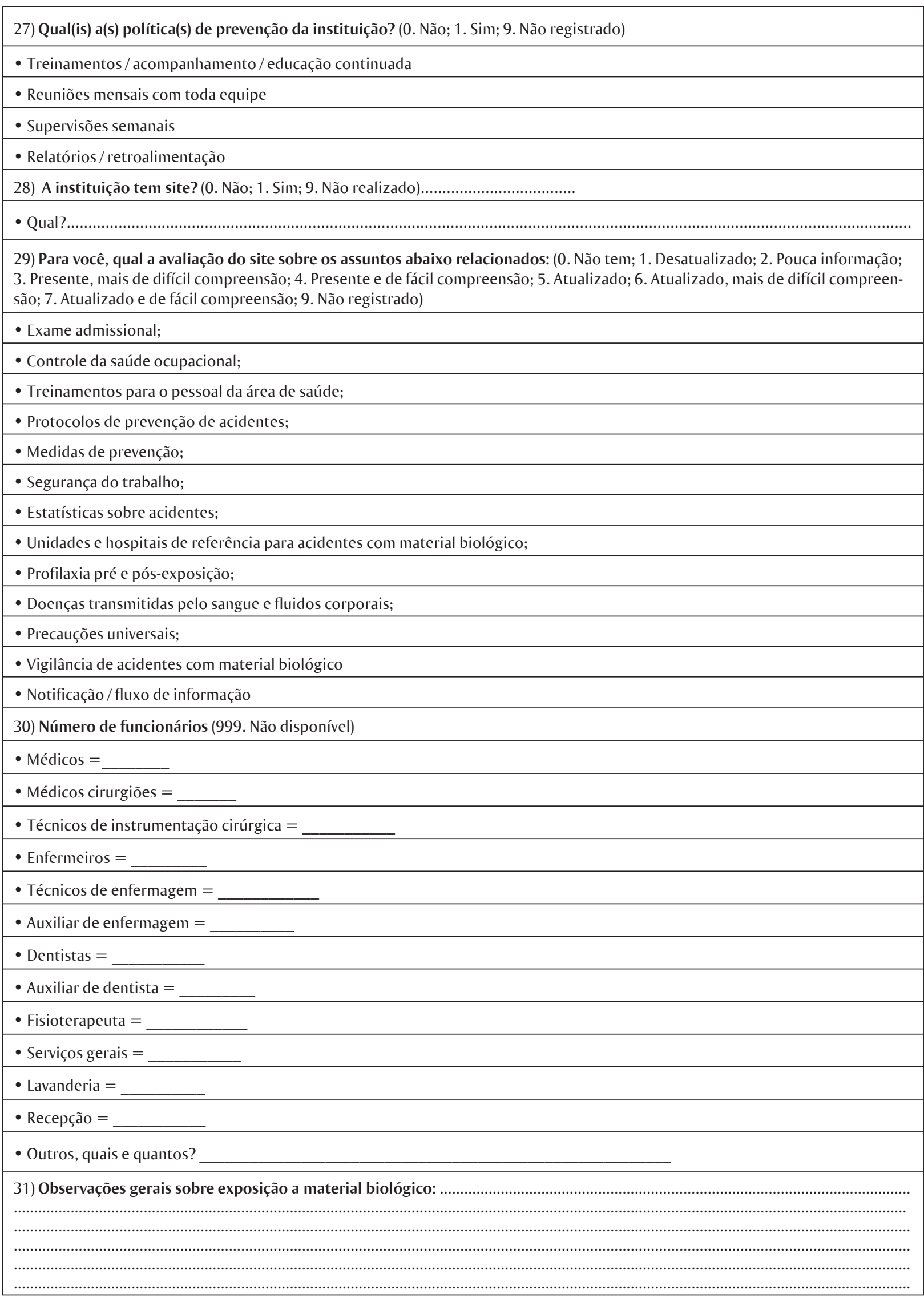


Apêndice 2 Questionário pessoal de saúde

Exposição ocupacional a material biológico: conhecimentos, atitudes e práticas do pessoal de saúde

\begin{tabular}{|c|}
\hline Dados gerais \\
\hline 1) Data: __ I _ I \\
\hline 2) № questionário: \\
\hline 3) Instituição (codificação posterior): \\
\hline Perfil profissional \\
\hline 4) Gênero................ (0. Feminino; 1. Masculino; 9. Não registrado) \\
\hline 5) Idade, em anos................. (999- não registrado) \\
\hline 6) Estado civil........... (0. solteiro; 1. casado; 2. divorciado, separado; 3. viúvo; 9. Não registrado) \\
\hline 7) Categoria profissional: ............................................................................ (99. Não informado) \\
\hline 8) Tempo de serviço................................................ (00. Se < 12meses; 99. Não informado) \\
\hline $\begin{array}{l}\text { 9) Situação nesta unidade de saúde.......................... (0. Empregado não registrado; } 1 \text {. Trabalho temporário; } 2 \text {. Autônomo; } 3 \text {. Empre- } \\
\text { gado registrado; 4. Cooperativado; } 5 \text {. Servidor público; } 9 \text {. Não informado) }\end{array}$ \\
\hline 10) Turno de trabalho nesta instituição (0. Não; 1 . Sim; 9. Não registrado) \\
\hline - Matutino \\
\hline - Vespertino \\
\hline - Noturno \\
\hline 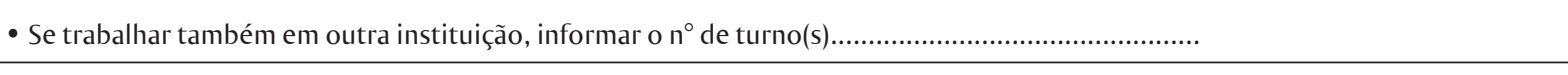 \\
\hline 11) Carga horária, média diária de trabalho nesta instituição............................ (99. Não registrado) \\
\hline • Se trabalhar também em outra(s) instituição(ões), informar a carga horária total................................ \\
\hline 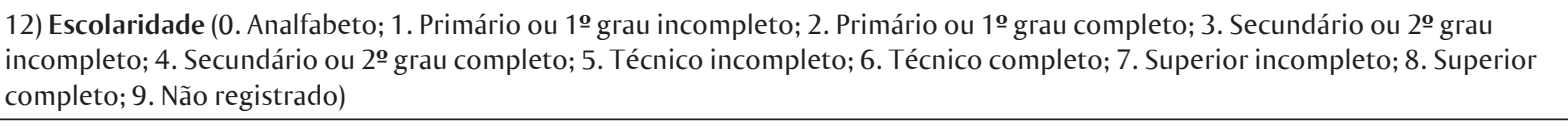 \\
\hline 13) Número de anos de estudo, inclusive se houver pós-graduação (99. Não registrado) \\
\hline $\begin{array}{l}\text { 14) Frequência de pausa durante o trabalho (0. Não faz pausa; } 1 \text {. Uma por turno; 2. Quando cansado; 3. Entre cada paciente; } 9 . \\
\text { Não registrado) }\end{array}$ \\
\hline 15) Quantos cursos de atualização você fez nos últimos dois anos? (9. Não registrado) \\
\hline 16) Quantos cursos sobre biossegurança você fez nos últimos dois anos? (9. Não registrado) \\
\hline Saúde do trabalhador \\
\hline $\begin{array}{l}\text { 17) Você faz seus exames preventivos com que periodicidade? (0. Não faz; } 1 \text {. Sem regularidade; } 2 \text {. Bianual; 3. Anual; } 4 \text {. Cada seis } \\
\text { meses; 9. Não informado) }\end{array}$ \\
\hline - Avaliação clínica \\
\hline • Exames laboratoriais (hemograma, glicemia, urina, colesterol, triglicérides, TGO, TGP) \\
\hline - Citologia oncótica (Papanicolau) para mulheres \\
\hline - Mamografia para mulheres \\
\hline - Exame de próstata para homens \\
\hline
\end{tabular}




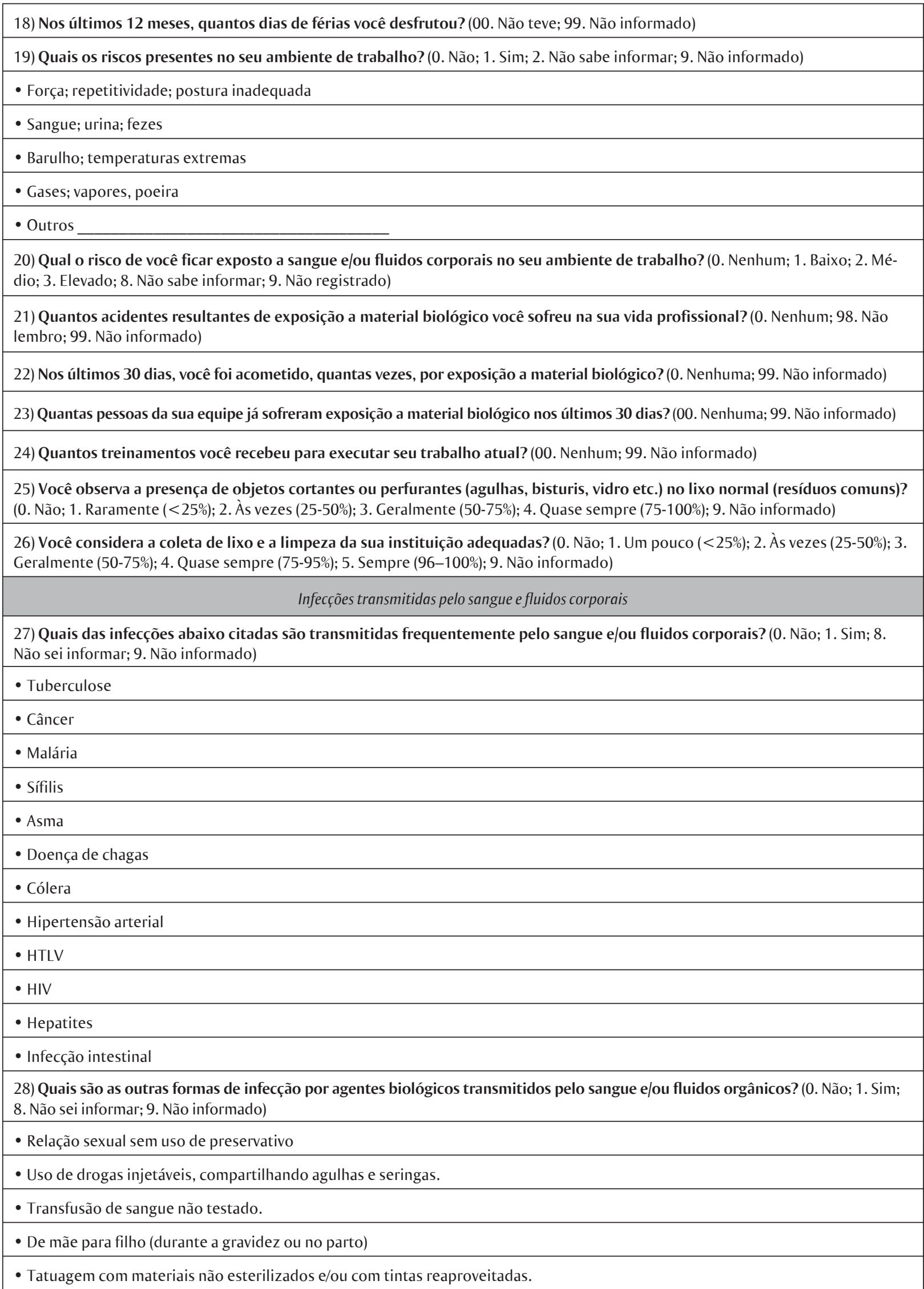




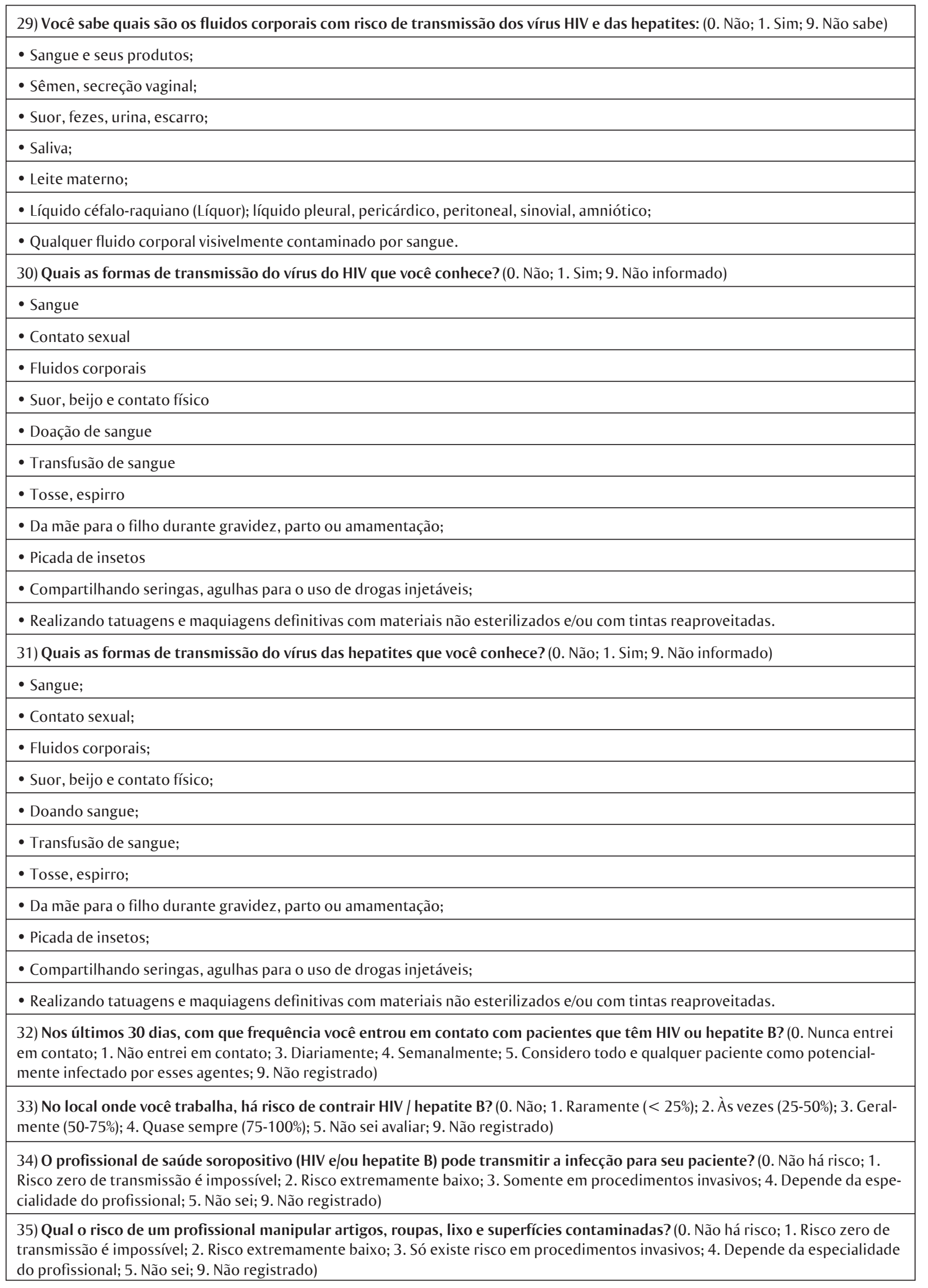


36) Como você define "precauções universais”? (0. Não sei definir; 1. Metodologia de abordagem; 2 . Medidas de prevenção para evitar acidentes e contaminações; 3. Cuidados na reutilização de instrumentos; 4. Uso rotineiro de luvas, máscara, batas, óculos; 9. Não informado)

37) Nas reuniões do seu setor de trabalho são discutidas as medidas de prevenção de acidentes com material biológico? (0. Não; 1. Raramente (<25\%); 2. Às vezes (25-50\%); 3. Geralmente (50-75\%); 4. Quase sempre (75-100\%); 9. Não informado)

38) Indique quais os fatores que influenciam na escolha do vestuário de proteção (0. Não; 1 . Sim; 9 . Não informado)

- Lesão por inoculação anterior

- Experiência passada

- Educação e treinamento

- Exemplo dado pelos colegas

- Exemplo estabelecido pelo pessoal com mais tempo na instituição

- Paciente tem infecção viral de origem sanguínea

- Paciente suspeito de ter infecção viral de origem sanguínea

- Avaliação do risco baseado em julgamentos relacionados com estilo de vida, orientação sexual ou nacionalidade.

- Avaliação do risco da probabilidade de exposição a sangue e outros fluidos corporais.

- Quantidade de tempo disponível

- Luvas interferem na destreza

- Disponibilidade de vestuário de proteção

- Precauções universais são desnecessárias devido à baixa incidência de infeç̧ões de origem sanguínea.

39) Os coletores especiais para descarte de material perfurocortante estão instalados ( 0 . Não há coletores especiais para descarte; 1. Existem, mas não estão instalados; 2 . Instalados em pontos inadequados, longe do local de procedimento; 3 . Em pontos inadequados, próximos ao local de procedimento; 4. Em pontos adequados, próximos ao local de procedimento; 9 . Não informado).

40) 0 uso de luvas, óculos de proteção, avental, interferem nas suas habilidades com os pacientes? (0. Não; 1 . Raramente $(<25 \%)$; 2. Às vezes (25-50\%); 3. Geralmente (50-75\%); 4. Quase sempre (75-100\%); 9. Não informado)

41) Você utiliza óculos de proteção, máscara e gorro em todos os procedimentos? (0. Não; 1. Raramente (< 25\%); 2 . Às vezes (2550\%); 3. Geralmente (50-75\%); 4. Quase sempre (75-100\%); 9. Não informado)

42) Você descarta as luvas após cada procedimento? (0. Não; 1. Raramente (<25\%); 2. Às vezes (25-50\%); 3. Geralmente (50-75\%); 4. Quase sempre (75-100\%); 9. Não informado)

43) Você lava suas mãos após contato direto com cada paciente? (0. Não; 1 . Raramente (<25\%); 2. Às vezes (25-50\%); 3. Geralmente (50-75\%); 4. Quase sempre (75-100\%); 9. Não informado)

\section{Exposição ocupacional}

44) Você avalia que problemas pessoais influenciam na sua rotina de trabalho? (0. Não; 1 . Raramente (< 25\%); 2. Às vezes (25-50\%); 3. Geralmente (50-75\%); 4. Quase sempre (75-100\%); 9. Não informado)

45) A exposição a material biológico acarreta transtorno na vida do profissional? (0. Não; 1 . Acarreta transtorno pelo risco de contaminação; 2. Pela expectativa dos exames; 3 . Reavaliação da profissão; 4. Revolta/medo; 5. Discriminação/Preconceito; 6 . Receio de demissão; 7. Críticas dos colegas da equipe; 9. Não informado)

46) Para você, quais os fatores que mais contribuem para os acidentes de trabalho? (0. Insatisfação profissional; 1 . Metas incompatíveis; 2. Ritmo de trabalho intenso; 3. Sobrecarga de trabalho; 4. Falta de treinamento; 5 . Horas extras excessivas; 6 . Mudança de função; 7. Acúmulo de função: 8. Falta de atualização; 9 . Falta de equipamentos individuais e coletivos; 10 . Sonolência; 11 . Chefia sem preocupação com o ser humano; 12. Pouca importância aos valores éticos no trabalho; 13. Falta de políticas de prevenção; 99. Não informado)

- Se houver mais de um, quais?.

47) Quantos acidentes você já sofreu envolvendo material perfurocortante? (00. Nenhum; 99. Não informado)

48) Quantos acidentes você já sofreu envolvendo respingos de sangue ou fluidos corporais? (00. Nenhum; 99. Não informado) 


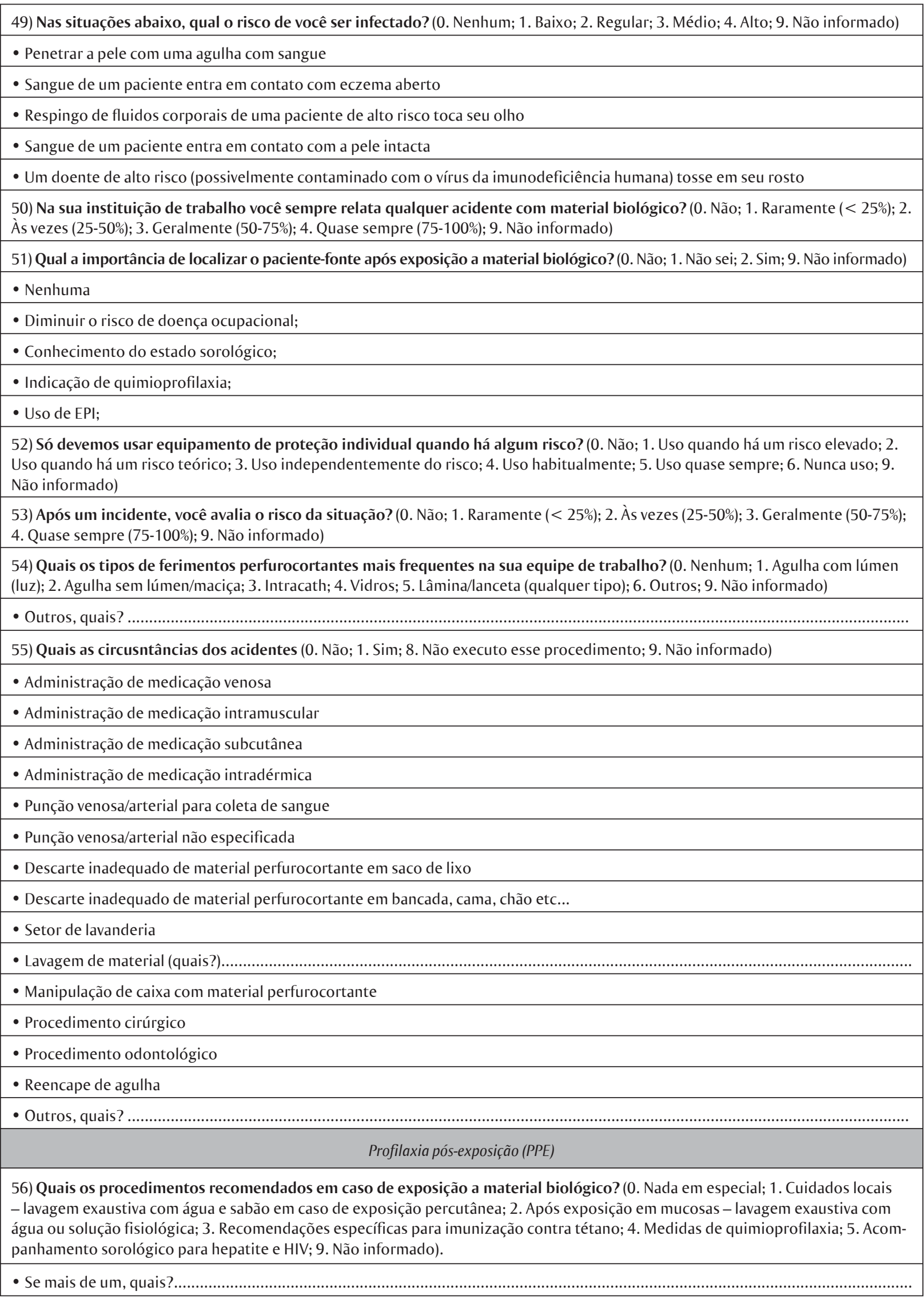


57) Quantas doses da vacina contra hepatite B você já usou? (0. Não sou vacinado; 98. Não sei; 99. Não informado).

58) A imunização da hepatite B é eficaz por quanto tempo (em anos)? (0. Não sei; 97. Por um longo tempo da vida; 98 . Por toda a vida; 99. Não informado)

59) Qual o risco de transmissão da hepatite B ao pessoal de saúde não imunizado e após exposição a material biológico: (0. Nenhum; 1. Baixo; 2. Médio; 3. Elevado; 8. Não sei; 9. Não informado)

60) Em caso de exposição a material biológico, a sua unidade de saúde possui insumos próprios de profilaxia pós-exposição (PPE) para hepatite B e HIV? (0. Não; 1. Raramente (<25\%); 2. Às vezes (25-50\%); 3. Geralmente (50-75\%); 4. Quase sempre (75-100\%); 9. Não informado)

61) Em caso de acidente, após avaliar o paciente-fonte e a gravidade ou o risco da exposição para HIV, em quantas horas depois deve-se iniciar a medicação antirretroviral? (0. Não sei; 98 . A qualquer tempo; 99 . Não informado)

62) Na dúvida da avaliação do risco da exposição para HIV, deve-se iniciar o esquema medicamentoso antirretroviral? (0. Não; 1 . Deve ser feita avaliação criteriosa por especialistas; 2. Deve-se avaliar a história prévia e atual; 3. Primeiro realizar sorologia do acidentado; 4 . Melhor começar a profilaxia e posteriormente reavaliar a manutenção ou a mudança do tratamento; 9 . Não informado)

\section{Notificação}

63) Em caso de exposição percutânea/mucocutânea, quando você deve relatar? (0. Eu não sei; 1 . Não importa quando; 2 . Quando tiver tempo, mesmo que seja horas ou dias depois; 3. Imediatamente após o acidente; 9 . Não informado)

64) A quem deve ser relatada uma exposição ocupacional a sangue e fluidos corporais? (0. Eu não sei; 1 . Para os parentes em casa; 2. Aos colegas no local de trabalho; 3. Para o chefe imediato; 4. Para o Núcleo de Epidemiologia do Hospital; 5. Para a Comissão ou Serviço de Controle de Infeç̧ão Hospitalar - CCIH; 6. Outros; 9. Não informado)

- Se outros, quais?

65) A ficha de notificação de acidentes com material biológico do SINAN (Sistema Nacional de Agravos de Notificação) é preenchida em qual setor? (0. Eu não sei; 1 . Pela direção clínica; 2. Pelo setor de enfermagem; 3. Pelo Núcleo de Epidemiologia do Hospital; 4. Pela Comissão ou Serviço de Controle de Infecção Hospitalar - CClH; 5. Outros; 9. Não informado)

- Se outros, quais?

66) 0 formulário específico de comunicação de acidentes de trabalho (CAT) é preenchido e encaminhado por qual setor? ( 0 . Eu não sei; 1. Pela direção clínica; 2. Pelo setor de enfermagem; 3. Pelo Núcleo de Epidemiologia do Hospital; 4. Pela Comissão de Controle de Infecção Hospitalar - CCIH; 5. Outros; 9. Não informado)

- Se outros, quais?

67) Você sabe para onde são encaminhadas as fichas do Sinan e do CAT? (0. Eu não sei; 1 . Ministério da Saúde; 2. Previdência Social; 3. CCIH; Vigilância Epidemiológica Municipal e Estadual; 4. Núcleo de Epidemiologia do Hospital; Secretaria Municipal e Estadual; 5. Outros; 9. Não informado)

- Se outros, quais?

68) Qual a importância de registrar o acidente com material biológico? (0. Eu não sei; 1. Subsidiar as ações de prevenção adequadas; 2. Planejamento para capacitações; 3 . Oferece subsídios para avaliação de situações de exposição; 4 . Ações e intervenções baseadas no diagnóstico situacional; 9 . Não informado)

69) Quais os fatores que contribuem e/ou determinam falhas no processo de notificação dos acidentes com material biológico? (0. Eu não sei; 1. Medo do risco de infecção; 2. Reavaliação da profissão; 3. Revolta/medo; 4. Discriminação/Preconceito; 5. Receio de demissão; 6. Críticas dos colegas da equipe; 9. Não informado)

70) Na instituição que você trabalha, está implantada a vigilância de acidentes com material biológico? (0. Não está implantada na instituição; 1. Esta em fase de implantação; 2. Está implantada há menos de 12 meses; 3 . Foi implantada há mais de 12 meses; 8. Não sei informar ou desconheço do que se trata; 9. Não registrado)

71) Você recebeu algum treinamento para monitoramento das ações de vigilância de acidentes com material biológico? (0. Nenhum; 1. Não esta implantada na instituição; 2. Conheço apenas a ficha de notificação; 3. Curso Básico de Vigilância Epidemiológica - CBVE; 4. Capacitação pela Secretaria Municipal e Estadual; Outros; 9. Não informado)

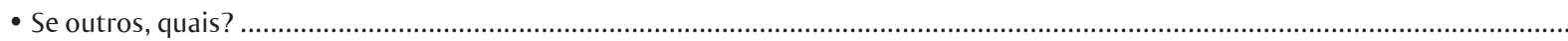

72) Qual a periodicidade dos informes e/ou boletins epidemiológicos divulgados para o pessoal de saúde? ( 0 . Nenhum; 1 . Anual; 2. Semestral; 3. Trimestral; 4. Bimensal; 5. Mensal; 6. Quinzenal; 7. Semanal; 8. Boletim diário via site da instituição ou diário por outro veículo; 9 . Não informado) 


\section{Políticas de prevenção}

73) Quais os métodos utilizados pela instituição para a prevenção da exposição a material biológico? (0. Nenhum; 1 . Treinamentos constantes para todo pessoal de saúde; 2. Vigilância de acidentes com material biológico; 3 . Equipamentos de proteção individuais e coletivos; 4 . Agulhas com dispositivo de segurança; 5 . Coletores especiais para descarte de material perfurocortante; 6 . Não informado)

74) Qual o número da norma regulamentadora (NR) que estabelece as diretrizes básicas para implementação de medidas de proteção à segurança e à saúde dos trabalhadores de saúde. (0. Não sei; 1. NR 4; 2. NR 7; 3. NR 9; 4. NR 32; 9. Não informado)

75) Qual o número da norma regulamentadora (NR) que estabelece a obrigatoriedade do programa de controle médico de saúde ocupacional - PCMSO. (0. Não sei; 1. NR 4; 2. NR 7; 3. NR 9; 4. NR 32; 9. Não informado)

76) Qual o número da norma regulamentadora (NR) que estabelece a obrigatoriedade do programa de prevenção de riscos ambientais - PPRA (0. Não sei; 1. NR 4; 2. NR 7; 3. NR 9; 4. NR 32; 9. Não informado)

77) Cite quais os protocolos da instituição em caso de exposição a material biológico

78) Na sua instituição há discussão, palestras, cursos sobre exposição ocupacional a material biológico? (0. Não; 1 . Raramente (< 25\%); 2. Às vezes (25-50\%); 3. Geralmente (50-75\%); 4. Quase sempre (75-100\%); 9. Não informado)

79) Para você, a prevenção ajuda a combater estigmas e preconceitos relacionados à exposição ocupacional com material biológico? (0. Não; 1. Raramente (<25\%); 2. Às vezes (25-50\%); 3. Geralmente (50-75\%); 4. Quase sempre (75-100\%); 9. Não informado)

80) Você acha que a adoção de uma prática de educação e informação junto aos trabalhadores, em seus locais de trabalho, ajuda na prevenção de acidentes? (0. Não; 1. Raramente (<25\%); 2. Às vezes (25-50\%); 3. Geralmente (50-75\%); 4. Quase sempre (75-100\%); 9. Não informado)

81) Tem outras informações? 